\title{
A new principle applied to the determination of calcium in biological materials by flame photometry
}

\author{
J. K. FAWCETT AND V. WYNN \\ From the Surgical Unit, St. Mary's Hospital, London
}

SYNOPSIS The effect of magnesium sulphate in releasing calcium emission from interference by phosphate and sulphate has been investigated.

Samples were diluted in $10 \mathrm{mM} \mathrm{MgSO}, 2 \mathrm{mM} \mathrm{NaCl}$, giving final calcium concentrations of about 0.05 to $0.10 \mathrm{mM}$. In this diluent, galvanometer readings were proportional to calcium concentrations up to $0.4 \mathrm{mM}$. The magnesium sulphate released calcium emission from depression by phosphate and sulphate. The excess sodium chloride eliminated enhancement of calcium emission by added sodium and potassium in the sample. Subtraction of background readings excluded direct interference.

A $3 \%$ correction was made for the effect of the viscosity of $1: 50$ plasma dilutions. Satisfactory recoveries of added calcium were obtained from plasma, urine, and faeces using the diluent described above. Results on urine and faeces correlated closely with those obtained by an EDTA titration method. Results on plasma were consistently $2 \%$ higher by flame photometry than by EDTA titration.

Other methods of calcium determination, depending on the use of radiation buffers or standard addition, were found to be unsatisfactory because of variable interference by phosphate at different calcium levels.

The measurement of calcium in biological materials by flame photometry is more difficult than that of sodium and potassium because of its lower emission energy and more serious interference by contaminating substances. The first difficulty can be overcome by using a high flame temperature, a prism monochromator, and a sensitive detector. Instruments incorporating these features permit the use of the weak calcium line at $422.7 \mathrm{~m} \mu$ where interference is less than using the calcium oxide bands at $554 \mathrm{~m} \mu$ and $622 \mathrm{~m} \mu$. Even at $422.7 \mathrm{~m} \mu$, however, there are three important sources of interference as follows:-

(1) Background (direct) interference: using a prism monochromator, this is due mainly to heterochromatic spectral radiation by sodium and potassium, only a fraction being due to scattered light. (2) Enhancement or depression of calcium emission (indirect interference): the emission by calcium itself is enhanced by sodium and potassium and depressed by certain anions, notably phosphate and sulphate.

Received for publication 21 November 1960.
(3) Alteration of the physical properties of the solution because the quantity and dispersal of the spray reaching the flame may be influenced by differences in viscosity and surface tension due to protein and other organic compounds.

Many procedures for measuring calcium by flame photometry involve prior separation of calcium from interfering substances by precipitation of calcium oxalate (Powell, 1953; Chen and Toribara, 1953; Butterworth, 1957; Woollen and Walker, 1959) or by means of a cation exchange resin (Brabson and Wilhide, 1954; Denson, 1954; Jackson and Irwin, 1957). These preliminary steps are time-consuming and have errors of their own, thus combining disadvantages of other methods for calcium determination with those of flame photometry, while losing the simplicity of the latter.

Apart from the separation of calcium from interfering substances, many methods have been introduced to control their effects, but none has been generally accepted. The complexity of interfering effects makes the calculation of correction factors 
(Severinghaus and Ferrebee, 1950) impracticable. Synthetic standards (Chen and Toribara, 1953; MacIntyre, 1954; Teloh, 1958), with a composition similar to that of the solutions analysed, cannot be used when the composition of the materials is widely variable. Internal standards (Baker, 1955) are of only limited value because few sources of interference affect calcium emission and that of the internal standard proportionately.

Background correction (Vallee, 1954; Margoshes and Vallee, 1956) is made by subtracting readings taken at wavelengths near the analytical wavelength from those taken at the analytical wavelength. This accounts for direct interference, but indirect interference effects present much greater difficulty.

Radiation buffers (Severinghaus and Ferrebee, 1950; MacIntyre, 1957), which incorporate an excess of interfering ions, can control sources of indirect interference which have no increased effect above certain concentrations of the interfering substance or which have a plateau region over a restricted range.

In the determination of magnesium, anion interference has been controlled (West and Cooke, 1960; Fawcett and Wynn, 1961) by adding a large excess of ethylene diamine tetra-acetic acid (EDTA). West and Cooke (1960) found that EDTA could also be applied in this way to the determination of calcium but that the excess had to be very much greater, 160 -fold instead of 10-fold. They used the disodium salt of EDTA, from which the high background emission is a serious disadvantage, particularly with instruments not equipped for automatic spectral scanning.

The standard addition method (Rothe and Sapirstein, 1955) may be used when the relationship between concentration and emission is linear, and sources of indirect interference have the same proportional effect upon standard calcium added to diluted samples as upon the calcium already present. The original concentration is thus calculated from the equation:

$\frac{\text { calcium in sample }}{\text { calcium added }}=\frac{\text { emission by sample }}{\begin{array}{c}\text { increase in emission due to } \\ \text { calcium added }\end{array}}$

We investigated the use of radiation buffers and the standard addition procedure but, as reported below, neither was found satisfactory for our purpose.

Mitchell and Robertson (1936) reported that high concentrations of strontium released calcium emission from the inhibitory effect of aluminium. Willis (1960), measuring calcium by atomic absorption spectroscopy, used strontium chloride to control phosphate interference, and we tested its use for the same purpose in flame photometry. We also explored the potentialities of other compounds and achieved the best results with magnesium sulphate, which is readily available in a calcium-free state.

Since we completed our investigation on a method of releasing calcium emission from anion inter- $\frac{C}{\sigma}$ ference, Dinnin (1960) has reported results of an investigation on alkaline earth and rare earth $\overparen{\nabla}$ elements, and iron, yttrium, and scandium as releasing agents, and he has proposed an explanation ${ }^{\circ}$ for their mode of action. The results of our investi- $\vec{O}$ gation are reported below.

\section{EXPERIMENTAL}

INSTRUMENTAL The Unicam SP 900 flame spectro- $\vec{A}$ photometer was used. It has a Meker type burner utilizing $\mathrm{c}$ acetylene and compressed air. The latter conveys the atomized solution from a separate spray chamber. The $\omega$ instrument is equipped with a fused silica prism mono- $\mathrm{O}$ chromator and a photomultiplier detector. A slit width of $0.08 \mathrm{~mm}$., corresponding to a nominal band width of $1 \mathrm{~m} \mu, \omega$ was selected for all experiments. Air pressure was $30 \frac{\mathbb{D}}{0}$ lb./in. ${ }^{2}$ and acetylene pressure was about $12 \mathrm{~cm}$. of water, $\underset{\mathbb{D}}{\mathbb{D}}$ except when the effect of altering flame conditions was being tested.

PREPARATION OF SAMPLES Samples were diluted to give $\vec{\varphi}$ a final calcium concentration of about 0.05 to $0.10 \mathrm{mM}$. $\rightarrow$ Plasma samples were obtained from heparinized blood 0 and diluted $1: 50$. Twenty-four-hour urine samples were preserved with $10 \mathrm{ml}$. of hydrochloric acid and diluted $1: 50$ or $1: 100$, according to the expected calcium $\bar{O}$ concentration. Faeces were prepared by homogenizing with water and transferring portions of about $2 \mathrm{~g}$. to $\varrho$ nickel crucibles of $50 \mathrm{~mm}$. diameter. The contents were $\overrightarrow{\vec{B}}$ dried at $105^{\circ}$ and ashed overnight in the uncovered $\frac{0}{3}$ crucibles at 475 to $525^{\circ}$. If magnesium, as well as calcium, $\bar{\supset}$ was to be determined, ashing was at 420 to $450^{\circ}$ because of loss of magnesium at higher temperatures (Fawcett and Wynn, 1961). The ash was dissolved by carefulo? boiling with $1 \mathrm{ml}$. of $1.0 \mathrm{~N}$. hydrochloric acid, transferred :quantitatively and diluted to $100 \mathrm{ml}$. This solution was 3 further diluted $1: 50$ to $1: 10$, according to the expected calcium concentration.

GALVANOMETER READINGS When special diluting solu-을 tions were used, standard calcium solutions were diluted $D$ in the same diluent as the samples, and this diluent was also used for zero-setting the galvanometer. Blank and $\mathrm{N}$ standard readings were checked between every two or $\mathscr{S}$ three readings of unknowns. Each dilution was read at $N$ least three times, and more often if any reading differed by more than $1 \%$ from the mean.

INTERFERENCE BY SODIUM AND POTASSIUM The effects of sodium were observed by adding various concentrations $\bar{\varnothing}$ of spectroscopically pure sodium chloride to deionized $\stackrel{\text { ? }}{+}$ water and to solutions containing $0.05 \mathrm{mM}$ and $0.10 \mathrm{mM}$ calcium chloride.

Sodium interference was of two kinds: direct inter- $\overrightarrow{\mathbb{D}}$ ference due to spectral radiation by sodium in the region $\frac{\rho}{D}$ of the calcium line, and indirect interference due to 
enhancement of calcium emission by sodium. It was found that direct interference by sodium was proportional to its own concentration and represented about $0.04 \%$ of the emission from equimolecular concentrations of calcium, under the conditions of the investigation. Ten $\mathrm{mM}$ sodium chloride gave identical readings at $422.7 \mathrm{~m} \mu$, $418 \mathrm{~m} \mu$, and $428 \mathrm{~m} \mu$, and readings at the latter two wavelengths were unaffected by calcium emission.

In contrast to the direct interference, the enhancement interference at any stated sodium level was directly proportional to calcium concentration. As the sodium concentration was raised, the percentage enhancement rose to a maximum of $9 \%$ at $1 \mathrm{mM}$, remaining at this percentage for sodium concentrations at least as high as $10 \mathrm{mM}$. This is shown in Fig. 1.

The interference effects of potassium were similar to those of sodium, and direct interference was corrected in the same way. In the presence of $2 \mathrm{mM}$ sodium chloride, as a radiation buffer, there was no further enhancement of calcium emission by added potassium up to $5 \mathrm{mM}$.

In subsequent investigations, direct interference was excluded by subtracting the mean of readings at $418 \mathrm{~m} \mu$ and $428 \mathrm{~m} \mu$ from readings at the calcium line, $422.7 \mathrm{~m} \mu$. Indirect interference by sodium and potassium was controlled by incorporating $2 \mathrm{mM} \mathrm{NaCl}$ in all standards and sample dilutions.

INTERFERENCE BY PHOSPHATE AND SULPHATE The effects of phosphate were observed by adding spectroscopically pure sodium dihydrogen phosphate to the solutions, and excluding the effects of sodium.

At any stated calcium concentration between 0.02 and $0.2 \mathrm{mM}$, the depression of calcium emission by phosphate was constant within the range 0.5 to $10 \mathrm{mM}$ phosphate. The percentage depression of calcium emission by phosphate increased, however, with calcium concentration. Added phosphate thus distorted the linear relationship between calcium concentration and emission, as shown in Fig. 2. The degree of distortion varied with flame conditions, such as the pressures of air and acety-

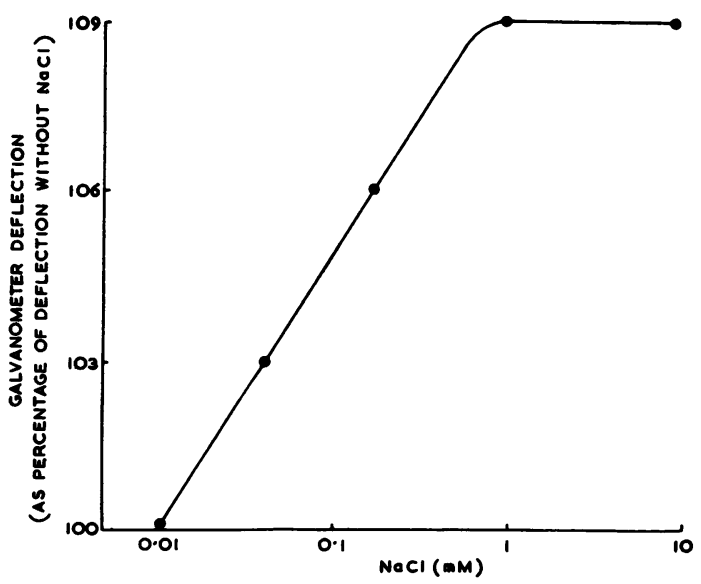

FIG. 1. Enhancement of calcium emission by sodium.

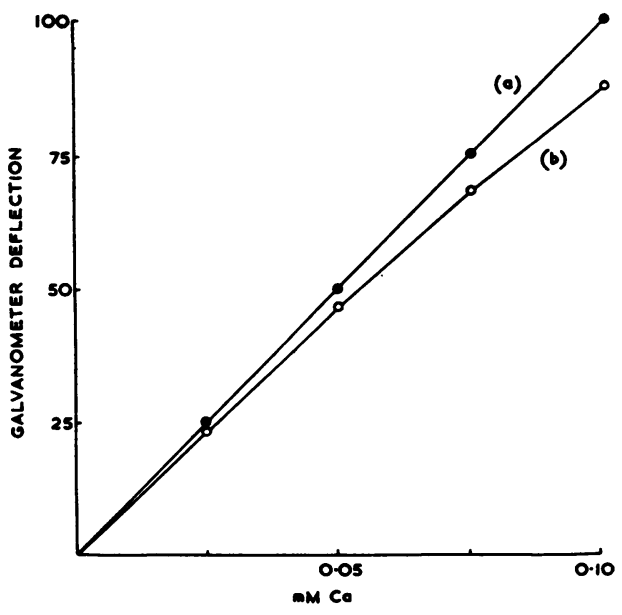

FIG. 2. Depression of calcium emission by phosphate. Curve (a): Calcium emission in absence of phosphate. Curve (b): Calcium emission in presence of $0.5 \mathrm{mM}$ $\mathrm{NaH}_{2} \mathrm{PO}_{4}$. Enhancement of calcium emission by $\mathrm{Na}$ was controlled by including $2 \mathrm{mM} \mathrm{NaCl}$ in all solutions.

lene, and it was difficult to reproduce exactly the same curve on different occasions.

Like phosphate, $10 \mathrm{mM}$ sulphuric acid or $10 \mathrm{mM}$ ammonium sulphate caused depression of calcium emission and distortion of the calibration curve. In the presence of $10 \mathrm{mM}$ sulphate, however, $1 \mathrm{mM}$ phosphate had no additional effect on calcium emission. Similarly, in the presence of $0.5 \mathrm{mM}$ sodium dihydrogen phosphate, as a radiation buffer, there was no further depression due to added sulphate up to $0.5 \mathrm{mM}$.

STANDARD ADDITION METHOD The standard addition method depends upon proportionality between calcium concentration and emission. As phosphate and sulphate caused distortion of the calcium calibration curve it was suspected that the method might not be valid when applied to biological materials. This was investigated as follows.

If the standard addition method were valid, the result calculated for any sample concentration should have been independent of the known quantity of standard calcium added. Therefore two different quantities were added to portions of three plasma samples and four urine samples diluted in water. The two results calculated for each sample were compared. These seven experiments were carried out on five different occasions, with slight variations in flame conditions.

Calcium concentrations were calculated as

and

$$
2.5 \mathrm{mM} \times \frac{E_{0}}{E_{1}-E_{0}} \text { (Formula 1) }
$$

$$
5.0 \mathrm{mM} \times \frac{E_{0}}{E_{2}-E_{0}} \text { (Formula 2) }
$$

where $\mathrm{E}_{0}=$ emission by sample diluted $1: 50$ in water, $\mathrm{E}_{1}=$ emission by the diluted sample incorporating 0.05 
$\mathrm{mM}$ calcium chloride, and $\mathrm{E}_{2}=$ emission by the diluted sample incorporating $\mathbf{0 \cdot 1 0} \mathrm{mM}$ calcium chloride.

Table I shows the results of these experiments. The two results for each sample concentration usually differed by 2 to $5 \%$. The non-linear relationship between calcium concentration and emission, in the presence of plasma or urine, is apparent from the last column of Table I. This

\section{TABLE I}

CALCULATION OF CALCIUM CONCENTRATION USING THE STANDARD ADDITION METHOD

Sample

\begin{tabular}{|c|c|}
\hline $\begin{array}{l}\text { Ca Concent } \\
(m M .)\end{array}$ & n of Sample \\
\hline $\begin{array}{l}\text { Calculated } \\
\text { from } \\
\text { Formula } 1\end{array}$ & $\begin{array}{l}\text { Calculated } \\
\text { from } \\
\text { Formula } 2\end{array}$ \\
\hline
\end{tabular}

\begin{tabular}{lllll}
\hline Plasma 1 & 1.74 & 1.74 & 0 & 1.00 \\
Plasma 2 & 2.52 & 2.57 & 2 & 1.04 \\
Plasma 3 & 2.72 & 2.85 & 5 & 1.10 \\
Urine 1 & 0.32 & 0.34 & 6 & 1.11 \\
Urine 2 & 0.55 & 0.56 & 2 & 1.03 \\
Urine 3 & 2.30 & 2.38 & 3 & 1.08 \\
Urine 4 & 5.00 & 5.33 & 7 & 1.13
\end{tabular}

shows that the increase $\left(E_{1}-E_{0}\right)$ in emission when the concentration was raised by $0.05 \mathrm{mM}$ was usually substantially greater than the additional increase $\left(E_{2}-E_{1}\right)$ on raising the concentration by a further $0.05 \mathrm{mM}$. These findings were consistent with the earlier observations that, in the presence of phosphate, calcium emission was no longer proportional to concentration.

CALCIUM RELEASE METHOD Phosphate interference in calcium emission was investigated with solutions diluted in $10 \mathrm{mM} \mathrm{SrCl}_{2}, 2 \mathrm{mM} \mathrm{NaCl}$, and in $10 \mathrm{mM} \mathrm{MgSO}_{4}, 2$ $\mathrm{mM} \mathrm{NaCl}$. Calcium emission was depressed by about $4 \%$ by $0.5 \mathrm{mM}$ phosphate in the former diluent but was not depressed at all in the latter.

Table II shows the release of calcium emission from the depressing effect of phosphate when the diluent contained $10 \mathrm{mM}$ magnesium sulphate. When the concentration of phosphate was raised above $2 \mathrm{mM}$, however, calcium emission decreased rapidly, and depression was very much greater than that caused by phosphate in the absence of magnesium sulphate. The concentration of phosphate which could be controlled varied with the concentration of magnesium sulphate. Ten mM magnesium sulphate was adequate to control phosphate interference at concentrations up to $100 \mathrm{mM}$ in samples diluted $1: 50$, or up to $200 \mathrm{mM}$ in samples diluted $1: 100$. Under the conditions of the investigation, the magnesium sulphate appeared to cause a $1 \%$ enhancement of the calcium emission.

With $2 \mathrm{mM}$ sodium chloride in the diluent, sodium concentrations at least as high as $\mathbf{4 0 0} \mathbf{m M}$ had no effect on calcium emission when samples were diluted $1: 50$. Table II also shows that hydrochloric acid depressed calcium emission by a maximum of $3 \%$, but the effect was negligible at concentrations of $1 \mathrm{mM}$ or less. This was about the concentration of hydrochloric acid in the final dilutions, when it was used as a urine preservative or to dissolve faecal ash.
TABLE II

EFFECT OF VARIATIONS IN COMPOSITION OF DILUENT ON EMISSION BY $0.10 \mathrm{mM} \mathrm{CaCl}_{2}$

$\mathrm{MgSO}_{4}(\mathrm{mM}) \quad \mathrm{NaCl}(\mathrm{mM}) \quad \mathrm{NaH}_{2} \mathrm{PO}_{4}(\mathrm{mM}) \quad \begin{aligned} & \text { Galvanometer } \\ & \text { Deflection }\end{aligned}$

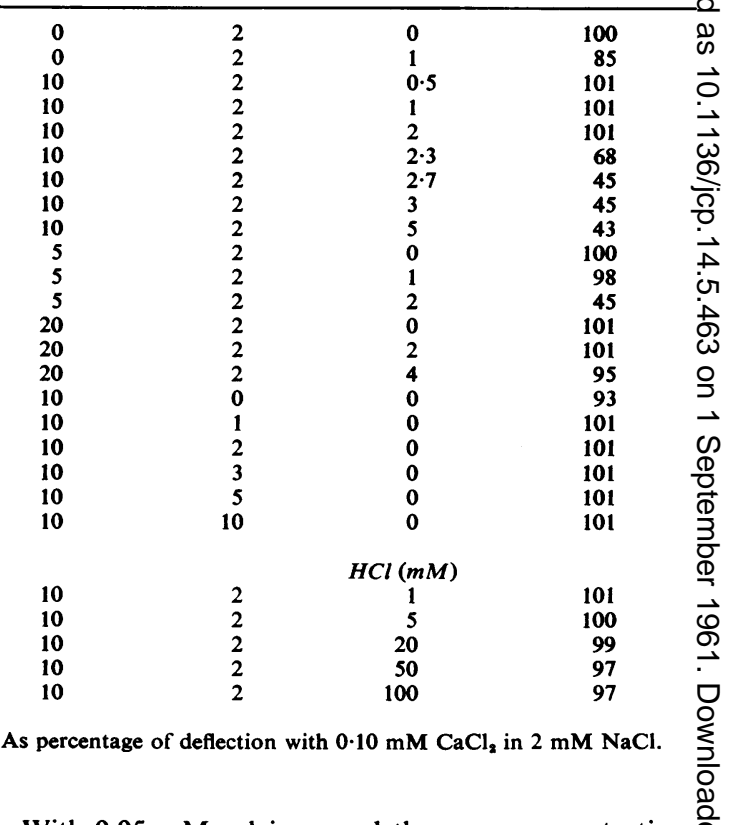

With $0.05 \mathrm{mM}$ calcium, and the same concentrations $\mathrm{D}$ of other solutes as those recorded in Table II, galvanometer deflections were one-half of those reported foro음

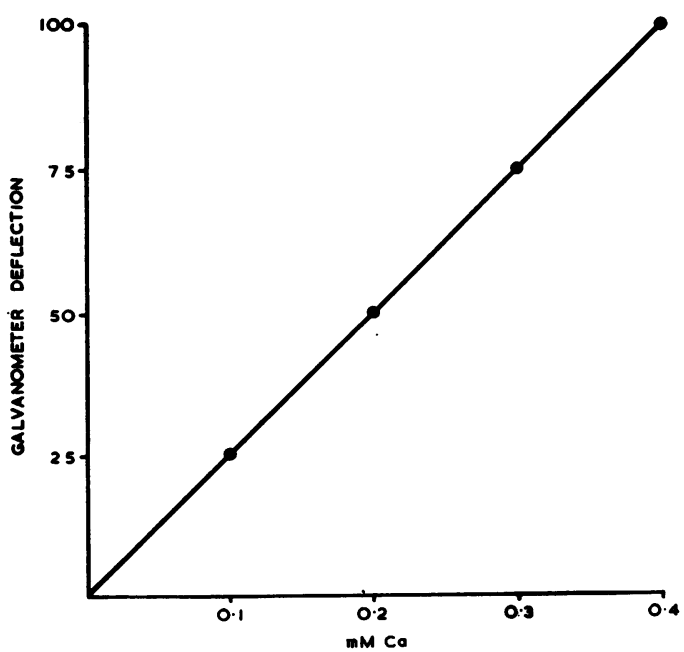

FIG. 3. Calibration curve, using $10 \mathrm{mM} \mathrm{MgSO}_{4}, 2 \mathrm{mM}$ $\mathrm{NaCl}$ as diluting solution. 
$0 \cdot 10 \mathrm{mM}$ calcium. The only occasion when calcium concentration and emission were not proportional was when phosphate was added in the absence of magnesium sulphate. In the presence of magnesium sulphate, however, even when phosphate concentration was so high that calcium emission was depressed, the percentage depression was the same at both calcium levels.

When a diluting solution containing $10 \mathrm{mM} \mathrm{MgSO}_{4}$, $2 \mathrm{mM} \mathrm{NaCl}$, was used, calcium emission was proportional to concentrations at least as high as $0.4 \mathrm{mM}$, the highest concentration which could be measured at the slit width of $0.08 \mathrm{~mm}$. The calibration curve is shown in Fig. 3 .

The background readings at $418 \mathrm{~m} \mu$ and $428 \mathrm{~m} \mu$ were usually about $2 \%$ of the readings at $422.7 \mathrm{~m} \mu$ for plasma and urine, but were usually negligible for faeces.

PLASMA VISCOSITY The effect of the viscosity of $1: 50$ dilutions of plasma on the results obtained was tested by comparing the rate of uptake of diluted plasma into the atomiser with that of standard solutions, and by comparing calcium results obtained with and without prior ashing of the plasma. The rate at which $1: 50$ plasma dilutions were drawn into the atomiser was found to be $3 \%$ less than the uptake rate of standard solutions. When seven samples of plasma were analysed both directly and after ashing, calcium emission from the unashed samples was an average of $3.6 \%$ (S.D. $1.6 \%$ ) less than the emission after ashing them.

The possibility that the lower surface tension of diluted plasma, compared with standard solutions, might affect the proportion of the aerosol reaching the flame was also investigated. A surface-active agent (Pluronic F 68) was added to a standard calcium solution to reduce the surface tension well below that of diluted plasma. Calcium emission in the flame, however, was not affected.

The physical properties of plasma dilutions thus depressed observed calcium results by 3 to $3.6 \%$, with the instrument used by us. A $3 \%$ correction factor was selected and the validity of this is supported by the results of the recovery experiments reported below, in which this correction factor was used.

\section{RESULTS}

RECOVERY EXPERIMENTS USING CALCIUM RELEASE METHOD Recovery experiments were carried out on 16 samples of plasma, 15 of urine, and 14 of faeces. Samples were prepared as described above, incorporating $1 \mathrm{ml}$. of a stock solution of $0.5 \mathrm{M} \mathrm{MgSO}_{4}$, $0 \cdot 1 \mathrm{M} \mathrm{NaCl}$, in each $50 \mathrm{ml}$. dilution. Dilutions were prepared in parallel, with the inclusion of known quantities of calcium. In the recovery experiments on faeces, calcium was added sometimes before ashing and sometimes afterwards, the results being reported separately. The experimentally determined viscosity factor was used in calculations of recoveries from plasma.

Results of the recovery experiments are reported in Tables III, IV, and V. Mean recoveries were
TABLE III

RECOVERIES OF CALCIUM ADDED TO

16 DILUTED PLASMA SAMPLES

\begin{tabular}{|c|c|c|}
\hline Ca Added A $^{1}(m)$ & Ca Recovered ${ }^{1}$ (mM) & Percentage Recovery \\
\hline $\begin{array}{l}1 \cdot 25 \\
1 \cdot 25 \\
1 \cdot 25 \\
2 \cdot 50 \\
2 \cdot 50 \\
2 \cdot 50 \\
2 \cdot 50 \\
2 \cdot 50 \\
2 \cdot 50 \\
2 \cdot 50 \\
2 \cdot 50 \\
2 \cdot 50 \\
2 \cdot 50 \\
2 \cdot 50 \\
2 \cdot 50 \\
2 \cdot 50\end{array}$ & $\begin{array}{l}1 \cdot 27 \\
1 \cdot 27 \\
1 \cdot 28 \\
2 \cdot 43 \\
2.44 \\
2.45 \\
2 \cdot 46 \\
2 \cdot 46 \\
2 \cdot 49 \\
2 \cdot 50 \\
2 \cdot 50 \\
2 \cdot 50 \\
2 \cdot 52 \\
2.53 \\
2.55 \\
2.56\end{array}$ & $\begin{array}{r}101.6 \\
101.6 \\
102.4 \\
97.2 \\
97.6 \\
98.0 \\
98.4 \\
98.4 \\
99.6 \\
100.0 \\
100.0 \\
100.0 \\
100.8 \\
101.2 \\
102.0 \\
102.4 \\
100.1 \\
1.9\end{array}$ \\
\hline
\end{tabular}

${ }^{1}$ In terms of apparent increase in plasma Ca concentration.

TABLE IV

RECOVERIES OF CALCIUM ADDED TO

15 DILUTED URINE SAMPLES

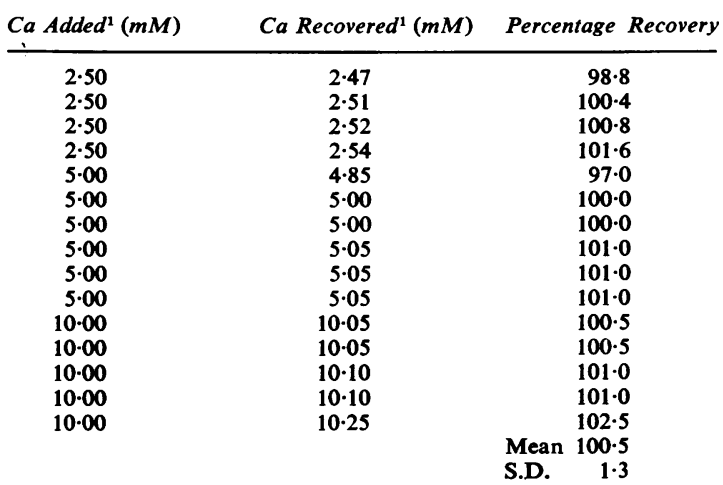

${ }^{1}$ In terms of apparent increase in urine Ca concentration.

\section{TABLE V}

RECOVERIES OF CALCIUM ADDED TO (a) SEVEN SAMPLES OF FAECES BEFORE AND (b) SEVEN SAMPLES OF FAECES AFTER ASHING

Ca Added $^{1}$ (m-mole) Ca Recovered ${ }^{1} \quad$ Percentage Recovery (m-mole)

\begin{tabular}{|c|c|c|c|c|}
\hline & (a) & (b) & (a) & (b) \\
\hline 10.0 & 9.9 & - & 99.0 & - \\
\hline 10.0 & - & 9.9 & - & 99.0 \\
\hline 10.0 & 9.9 & $10 \cdot 1$ & 99.0 & 101.0 \\
\hline 10.0 & $10 \cdot 0$ & $10 \cdot 2$ & $100 \cdot 0$ & 102.0 \\
\hline $10 \cdot 0$ & $10 \cdot 0$ & 9.9 & $100 \cdot 0$ & 99.0 \\
\hline $20 \cdot 0$ & $19 \cdot 4$ & $19 \cdot 5$ & $97 \cdot 0$ & 97.5 \\
\hline $20 \cdot 0$ & - & $20 \cdot 3$ & - & $101 \cdot 5$ \\
\hline $75 \cdot 0$ & $75 \cdot 0$ & 76.0 & $100 \cdot 0$ & $101 \cdot 3$ \\
\hline $125 \cdot 0$ & 123.0 & - & 98.4 & - \\
\hline & & & 99.1 & $100 \cdot 2$ \\
\hline
\end{tabular}

In terms of apparent increase in daily output. 
$100.1 \%$ for plasma, $100.5 \%$ for urine, $99.1 \%$ for faeces to which calcium was added before ashing, and $100.2 \%$ for faeces to which calcium was added after ashing. Standard deviations were less than $2 \%$.

COMPARISON BETWEEN RESULTS OBTAINED BY CALCIUM RELEASE METHOD AND BY EDTA TITRATION The results of 26 calcium determinations on plasma, 10 on urine, and 11 on faeces obtained by flame photometry using the $10 \mathrm{mM} \mathrm{MgSO}_{4}, 2 \mathrm{mM} \mathrm{NaCl}$, diluent were compared with those obtained by titration with EDTA. The method for plasma was direct titration at $\mathrm{pH} 12$ with automatic detection of the end-point (Wootton and Haslam, to be published).The method for urine and faeces was the back-titration of a measured excess of EDTA with a standard calcium solution at $p \mathrm{H} 12$ using a calcein-thymolphthalein indicator.

Results of this comparison are recorded in Tables VI, VII, and VIII. Values for plasma were consistently $2 \%$ higher by flame photometry than by titration, but the differences with urine and faeces were small and unsystematic.

\section{TABLE VI}

COMPARISON OF RESULTS ON 26 PLASMA SAMPLES OF CALCIUM DETERMINATIONS BY FLAME PHOTOMETRY, USING THE CALCIUM RELEASE METHOD, AND BY FDTA TITRATION

Calcium Concentration ( $m M$ )

Difference $(m M)$

\begin{tabular}{|c|c|c|}
\hline $\begin{array}{c}\text { By Flame Photometry } \\
\text { (a) }\end{array}$ & $\begin{array}{c}\text { By } E D T A \\
(b)\end{array}$ & $(a-b)$ \\
\hline $\begin{array}{l}1 \cdot 22 \\
1 \cdot 37 \\
2 \cdot 18 \\
2 \cdot 32 \\
2 \cdot 35 \\
2 \cdot 35 \\
2 \cdot 37 \\
2 \cdot 38 \\
2 \cdot 42 \\
2 \cdot 43 \\
2 \cdot 43 \\
2 \cdot 45 \\
2 \cdot 46 \\
2 \cdot 49 \\
2 \cdot 52 \\
2 \cdot 55 \\
2 \cdot 55 \\
2 \cdot 62 \\
2 \cdot 68 \\
2 \cdot 69 \\
2 \cdot 70 \\
2 \cdot 76 \\
2 \cdot 77 \\
2 \cdot 82 \\
2 \cdot 95 \\
3 \cdot 46\end{array}$ & $\begin{array}{l}1 \cdot 17 \\
1 \cdot 32 \\
2 \cdot 15 \\
2 \cdot 27 \\
2 \cdot 30 \\
2 \cdot 30 \\
2 \cdot 32 \\
2 \cdot 33 \\
2 \cdot 35 \\
2 \cdot 32 \\
2 \cdot 42 \\
2 \cdot 39 \\
2 \cdot 43 \\
2 \cdot 44 \\
2 \cdot 52 \\
2 \cdot 52 \\
2 \cdot 55 \\
2 \cdot 60 \\
2 \cdot 60 \\
2 \cdot 62 \\
2 \cdot 62 \\
2 \cdot 72 \\
2 \cdot 70 \\
2 \cdot 75 \\
2 \cdot 88 \\
3 \cdot 42\end{array}$ & $\begin{array}{r}+0.05 \\
+0.05 \\
+0.03 \\
+0.05 \\
+0.05 \\
+0.05 \\
+0.05 \\
+0.05 \\
+0.07 \\
+0.11 \\
+0.01 \\
+0.06 \\
+0.03 \\
+0.05 \\
0 \\
+0.03 \\
0 \\
+0.02 \\
+0.08 \\
+0.07 \\
+0.12 \\
+0.04 \\
+0.07 \\
+0.07 \\
+0.07 \\
+0.04 \\
+0.05 \\
\text { Mean } \\
+0.05 \\
0.03\end{array}$ \\
\hline
\end{tabular}

${ }^{13} \%$ was added to each observed result by flame photometry to correct for the effect of plasma viscosity.

\section{TABLE VII}

COMPARISON OF RESULTS ON 10 URINE SAMPLES OF CALCIUM DETERMINATIONS BY FLAME PHOTOMETRY, USING CALCIUM RELEASE METHOD, AND BY EDTA TITRATION

Calcium Concentration (mM)

Difference $(m M)$

\begin{tabular}{ccc}
$\begin{array}{c}\text { By Flame Photometry } \\
(a)\end{array}$ & $\begin{array}{c}\text { By EDTA } \\
(b)\end{array}$ & $(a-b)$ \\
\hline 0.32 & 0.26 & +0.06 \\
0.40 & 0.44 & -0.04 \\
0.57 & 0.57 & 0 \\
3.86 & 3.81 & +0.05 \\
3.93 & 4.05 & -0.12 \\
4.15 & 4.15 & 0 \\
4.98 & 4.89 & +0.09 \\
4.94 & 5.00 & -0.06 \\
5.01 & 5.20 & -0.19 \\
7.61 & 7.81 & -0.20 \\
& & Mean -0.04 \\
& & S.D. 0.10
\end{tabular}

TABLE VIII

COMPARISON OF RESULTS ON 11 SAMPLES OF FAECES OF $\mathbb{D}$ CALCIUM DETERMINATIONS BY FLAME PHOTOMETRY, USING CALCIUM RELEASE METHOD, AND BY EDTA TITRATION $\stackrel{\mathbb{C}}{-}$ Calcium Output (m-mole/day)

\begin{tabular}{|c|c|c|}
\hline $\begin{array}{c}\text { By Flame Photometry } \\
(a)\end{array}$ & $\underset{(b)}{B y E D T A}$ & $\begin{array}{r}(m-m o l e / \text { day }) \\
(a-b)\end{array}$ \\
\hline $\begin{array}{r}1.5 \\
3.3 \\
8.2 \\
9.0 \\
11.4 \\
14.7 \\
20.1 \\
20.2 \\
21.9 \\
63.0 \\
76.0\end{array}$ & $\begin{array}{r}1.6 \\
3.3 \\
8.3 \\
8.7 \\
10.7 \\
14.0 \\
19.9 \\
20.3 \\
21.5 \\
61.5 \\
76.0\end{array}$ & $\begin{array}{cc} & -0.1 \\
& 0 \\
& 0.1 \\
& +0.3 \\
& +0.7 \\
& +0.7 \\
+0.2 & \\
+0.1 \\
-0.1 \\
+0.4 \\
+1.5 \\
0 \\
\text { Mean } & +0.3 \\
\text { S.D. } & 0.4\end{array}$ \\
\hline
\end{tabular}

DISCUSSION

The proper control of interference effects in the determination of calcium in biological materials by flame photometry requires that each source of inter-윽 ference should be considered individually. Allowance $>$ can be made for differences in the physical properties? of solutions and, when a monochromator is used, it $N$ is simple to correct for direct interference by sub- tracting background readings. Enhancement of 0 calcium emission by cations can be kept constant by taking advantage of the plateau effect. Anions, such as phosphate and sulphate, which depress calciumo emission, present a more difficult problem because of their variable influence at different calcium levels.?

The effect of phosphate in distorting the linear 0 relationship between calcium emission and concen-O tration was noted by Jackson and Irwin (1957). The data of Baker and Johnson (1954) are difficult to $\stackrel{\mathbb{Q}}{\mathcal{Q}}$ interpret in this respect because, while their Fig. 20 
shows that percentage depression by phosphate increased with increasing calcium concentration, at similar phosphate levels their Fig. 7 shows a linear relationship between calcium emission and concentration. Other workers (Chen and Toribara, 1953; Denson, 1954; Margoshes and Vallee, 1956; MacIntyre, 1957; Teloh, 1958) reported the effect of phosphate at a single calcium level and did not refer to distortion of the calibration curve.

Reports on the quantitative aspects of phosphate interference are generally conflicting. Although this might be attributed partly to the diversity of instruments and conditions used, it is noteworthy that Jackson and Irwin (1957), who observed nonproportionality of calcium concentration and emission in the presence of phosphate, employed a system different from our own, namely, a Beckmann DU spectrophotometer, a hydrogen-oxygen flame, and a wavelength of $554 \mathrm{~m} \mu$.

If the distorting effect of phosphate has sometimes been overlooked, this might help to account for the large discrepancies which have been found between results of flame photometry and of other methods, to which Hunter (1958) and Willis (1960) have drawn attention. Our findings agree well with those obtained by EDTA titration, even the $2 \%$ discrepancy with plasma being much less than that reported by others.

Of the known methods of controlling indirect interference effects in flame photometry, the use of radiation buffers or the addition of standard calcium to the samples, seemed to us the most hopeful. We found, however, that calibration curves using radiation buffers in the presence of phosphate were difficult to reproduce on different occasions, an effect which we attributed to variations in flame conditions. The standard addition method also proved unsound because of the non-proportionality of calcium concentration and emission in the presence of phosphate. Further disadvantages of this method were the superimposition of errors because of its dependence upon differences between large values, and the necessity to prepare a standard for each sample, even in a large series.

In the method presented here, calcium emission was released from depression by phosphate by the addition of a large excess of magnesium sulphate. This also eliminated any effect on calcium emission by the much smaller quantities of sulphate and magnesium ions already in the samples. When 10 $\mathrm{mM} \mathrm{MgSO}, 2,2 \mathrm{mM} \mathrm{NaCl}$ was used for zero-setting and dilution of standards and samples, and when simple corrections were made for direct background interference and viscosity effects, the results obtained on biological materials were independent of variations in the concentration of interfering substances likely to be encountered.
Dinnin (1960) has published a comprehensive report on releasing effects in flame photometry. Although he used strontium and praseodymium and not magnesium salts in quantitative analysis for calcium, he drew attention to the potentialities of magnesium in this connexion, particularly because of its low background emission in the region of the calcium line.

Dinnin's explanation of the mechanism of releasing effects is based upon chemical equilibria in the evaporating droplets of solution, involving an exchange of anions between calcium and the releasing cation. Two of our observations seem inconsistent with this explanation. Although magnesium was added in the form of the sulphate, there was no depression of calcium emission. In the presence of $10 \mathrm{mM}$ magnesium sulphate, there was a sudden and large depression of calcium emission when the concentration of phosphate was raised above $2 \mathrm{mM}$, and this occurred at calcium concentrations of both $0.05 \mathrm{mM}$ and $0.10 \mathrm{mM}$. This behaviour seemed more consistent with stoichiometric reactions involving magnesium and phosphate ions, in which calcium played no direct part, than with the displacement of equilibria. These theoretical aspects of calcium release are being investigated further.

The flame spectrophotometer used in this study was kindly lent to us by Unicam Instruments Ltd.

We thank Dr. P. H. Sanderson who carried out the EDTA titrations on plasma, Mr. P. B. Wells and Mr. H. Thomas who carried out the EDTA titrations on the samples of urine and faeces, and Mr. J. A. Corbett who drew our attention to the work of Dr. J. B. Willis on flame absorption spectroscopy.

\section{REFERENCES}

Baker, G. L., and Johnson, L. H. (1954). Analyt. Chem., 26, 465. Baker, R. W. R. (1955). Biochem. J., 59, 566.

Brabson, J. A., and Wilhide, W. D. (1954). Analyt. Chem., 26, 1060. Butterworth, E. C. (1957). J. clin. Path., 10, 379.

Chen, P. S., and Toribara, T. Y. (1953). Analyt. Chem., 25, 1642.

Denson, J. R. (1954). J. biol. Chem., 209, 233.

Dinnin, J. I. (1960). Analyt. Chem., 32, 1475.

Fawcett, J. K., and Wynn, V. (1961). J. clin. Path. 14, 403.

Hunter, G. (1958). Nature (Lond.), 182, 263.

Jackson, W. P. U., and Irwin, L. (1957). J. clin. Path., 10, 383.

MacIntyre, I. (1954). Biochem. J., 56, xliii.

- (1957). Ibid, 67, 164.

Margoshes, M., and Vallee, B. L. (1956). Meth. biochem. Anal., 3, 353.

Mitchell, R. L., and Robertson, I. M. (1936). J. Soc. chem. Ind. (Lond.), 55, $269 \mathrm{~T}$.

Powell, F. J. N. (1953). J. clin. Path., 6, 286.

Rothe, C. F., and Sapirstein, L. A. (1955). Amer. J. clin. Path., 25, 1076.

Severinghaus, J. W., and Ferrebee, J. W. (1950). J. biol. Chem., 187, 621.

Teloh, H. A. (1958). A.M.A. Arch. Path., 66, 474.

Vallee, B. L. (1954). Nature (Lond.), 174, 1050.

West, A. C. and Cooke, W. D. (1960). Analyt. Chem., 32, 1471.

Willis, J. B. (1960). Nature (Lond.), 186, 249.

Woollen, J. W., and Walker, P. G. (1959). J. clin. Path., 12, 149.

Wootton, I. D. P., and Haslam, R. M. To be published. 